\title{
An Ultra-Wideband Conformal Meandered Loop Antenna for Wireless Capsule Endoscopy
}

\author{
Soyeon Kim· Hyunchol Shin*
}

\begin{abstract}
This work presents an ultra-wideband conformal meandered loop antenna for wireless capsule endoscopy applications. The proposed antenna surrounds the outer wall of a capsule, so that the inner space can be used by a battery and other electrical and optical components. Fabricated on a flexible substrate, the antenna has a diameter of $10 \mathrm{~mm}$ and a height of $14 \mathrm{~mm}$ when wrapped around a cylindrical capsule. The antenna achieves an ultra-wide impedance bandwidth of $200 \mathrm{MHz}-2.05 \mathrm{GHz}$ (164\% of the fractional bandwidth), which provides sufficient coverage for the medical implant communication service, MedRadio, and industrial-scientific-medical (ISM) bands. This antenna also ensures robustness to the detuning effect, which could be caused by the inner components of the capsule and the outer environment variations. The omnidirectional radiation pattern of the antenna is verified by simulations and measurements, and its maximum gain is $-31.5 \mathrm{dBi}$. The fabricated antenna is successfully tested in an over-the-air wireless communication link, proving that the antenna can be instrumental in wireless capsule endoscopy applications.
\end{abstract}

Key Words: Capsule Endoscopy, Conformal Antenna, Meandered Loop Antenna, MICS, Wideband.

\section{INTRODUCTION}

Compared with the conventional wired cable-connected endoscopies, capsule endoscopy provides better diagnoses and treatments throughout the entire gastrointestinal (GI) tract in a minimally invasive way, thus causing less discomfort and less pain to patients [1]. Recent wireless capsule endoscopies have been developed to capture higher-quality wide-view-angle medical images and to communicate with external receivers with higher energy efficiency in a small capsule size [2]. The typical frequency bands for the wireless capsule endoscopes are 401$406 \mathrm{MHz}$ for the medical implant communication service (MICS) and MedRadio, and $433 \mathrm{MHz}$ for the industrialscientific-medical (ISM) services. As the capsule size is electri- cally very small compared with the frequency band, the antenna design significantly affects the form factor, wireless communication quality, and energy efficiency of the capsule. In addition, the impedance bandwidth of a capsule antenna should be wide. When the capsule travels through various tissue environments with different dielectric properties, it usually experiences an unstable contact condition in the GI tract. Then, the capsule antenna experiences severe impedance changes, which may lead to significant changes in the antenna characteristics. An ultra-wide bandwidth can mitigate such detuning effects.

In this work, we propose a conformal meandered loop antenna with a very wide bandwidth for sufficiently covering the MICS, MedRadio, and ISM bands. The antenna resonance performances, such as return loss and radiation patterns, are validated through simulations and measurements. The fabricat-

Manuscript received October 25, 2018 ; Revised December 4, 2018 ; Accepted December 17, 2018. (ID No. 20181025-074J)

Department of Electronics Convergence Engineering, Kwangwoon University, Seoul, Korea.

"Corresponding Author: Hyunchol Shin (e-mail: hshin@kw.ac.kr)

This is an Open-Access article distributed under the terms of the Creative Commons Attribution Non-Commercial License (http://creativecommons.org/licenses/by-nc/4.0) which permits unrestricted non-commercial use, distribution, and reproduction in any medium, provided the original work is properly cited.

(c) Copyright The Korean Institute of Electromagnetic Engineering and Science. All Rights Reserved. 
ed antenna is successfully verified in a $400-\mathrm{MHz}$ over-the-air communication link system and proved to meet the requirements for capsule endoscopy applications.

\section{ANTENNA DESIGN}

One possible design approach for the capsule antenna is to embed an antenna inside a capsule [3-5]. However, the embedded type is usually not desired because the antenna dimension is inevitably limited and confined by the internal space of the capsule, which easily leads to the antenna performance degradation. Moreover, the internal antenna reduces the remaining inner space that is used by the battery and the electronic and optical components. This problem can be avoided by employing a conformal-type antenna. Previous conformal antennas for capsule endoscopes were based on a microstrip patch type [6-9], meandered line type, [10-13] and meandered loop type [14-17].

The patch type is usually a narrow band (only a small \%), and always requires a solid ground plane that can block the camera view angle $[6,7]$. A slight enhancement of the bandwidth was reported in $[8,9]$, but the technique was only implemented at a much higher frequency and not in the frequency of interest of this work (i.e., MICS, MedRadio, and ISM bands). The meandered line antennas showed a wider bandwidth and a smaller dimension. However, the meandered line antennas in $[10,11]$ were also realized in a higher frequency region.

Achieving a wide impedance bandwidth is important for capsule endoscopes because the dielectric property of human tissues is highly dispersive, showing significant changes with respect to different tissues and frequencies [14]. To cope with the highly dispersive property, a magnetic antenna in a loop structure is known to be less sensitive to the permittivity change. Thus, the loop antennas operating in the $400 \mathrm{MHz}$ band were found to be effective, as they demonstrated a relatively wide bandwidth [15-
17]. Accordingly, in this work, we have chosen the loop antenna structure.

Fig. 1 shows the proposed loop antenna structure. Many meanderings are employed to realize a large electrical length while fitting to the outer dimension of the capsule. Fig. 1(a) shows the planar view. As the substrate is flexible, the planar structure can be wrapped in a cylindrical form, the front and back views of which are shown in Fig. 1(b) and (c). Fig. 1(d) presents the antenna dimensions. As shown in Fig. 1(b) and (c), the height and the diameter are $14 \mathrm{~mm}$ and $10 \mathrm{~mm}$, which correspond to $0.152 \lambda$ and $0.109 \lambda$ respectively, with respect to the in-body wavelength $\lambda$ of $91.7 \mathrm{~mm}$. Note that the effective wavelength inside the human body is significantly smaller than that in free space because of the high permittivity (about 56.8) of the human body tissue, which has a dielectric loading effect [15]. The antenna is designed and fabricated in a polytetrafluoroethylene (PTFE) substrate with a thickness of $254 \mu \mathrm{m}$, relative permittivity $\varepsilon_{r}$ of 2.17 , and loss tangent tan $\delta$ of 0.0009 . The copper thickness is $35 \mu \mathrm{m}$. The substrate is sufficiently flexible, and thus it can be bent and wrapped in a cylindrical form.

As the capsule travels in the GI tract, such as in the esophagus, stomach, colon, and small intestine, the capsule antenna experiences different human tissues with different dielectric properties and highly dispersive characteristics $[14,18]$. The resonance characteristics of the proposed antenna are examined in various human tissue models, such as the stomach $\left(\varepsilon_{r}=67.19\right.$ and $\tan \delta=0.62)$, colon $\left(\varepsilon_{r}=62.01\right.$ and $\left.\tan \delta=0.58\right)$, small intestine $\left(\varepsilon_{r}=65.2\right.$ and $\left.\tan \delta=1.22\right)$, and human phantom $\left(\varepsilon_{r}=\right.$ 56.87 and $\tan \delta=0.59)$. The antenna is assumed to be placed at the center of a cylindrical human tissue model with a height of $120 \mathrm{~mm}$ and a diameter of $120 \mathrm{~mm}$. Fig. 2 shows the simulated return losses in the four different tissue conditions. As can be seen, the proposed antenna exhibits a very wide bandwidth over the different tissue environments. The impedance bandwidth

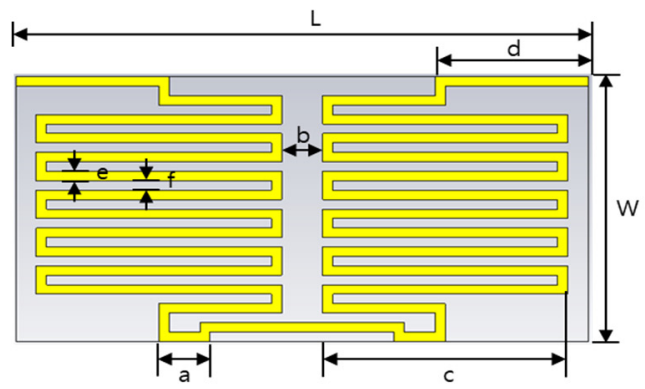

(a)

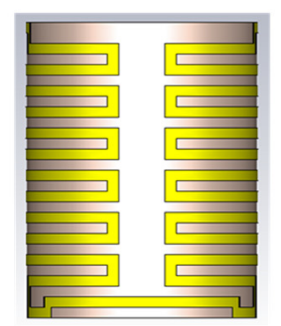

(b)

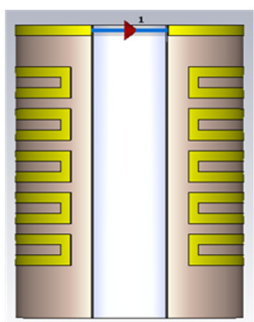

(c)

\begin{tabular}{|c|c|c|c|c|c|c|c|c|}
\hline Parameters & L & W & a & b & c & d & e & f \\
\hline Dimension $(\mathrm{mm})$ & 28 & 14 & 2.5 & 2 & 12 & 7.5 & 0.5 & 0.5 \\
\hline
\end{tabular}

(d)

Fig. 1. Geometric design of the proposed antenna: (a) planar view, (b) front-side view when wrapped in a cylindrical form, (c) back-side view when wrapped in a cylindrical form, and (d) dimensional parameters. 


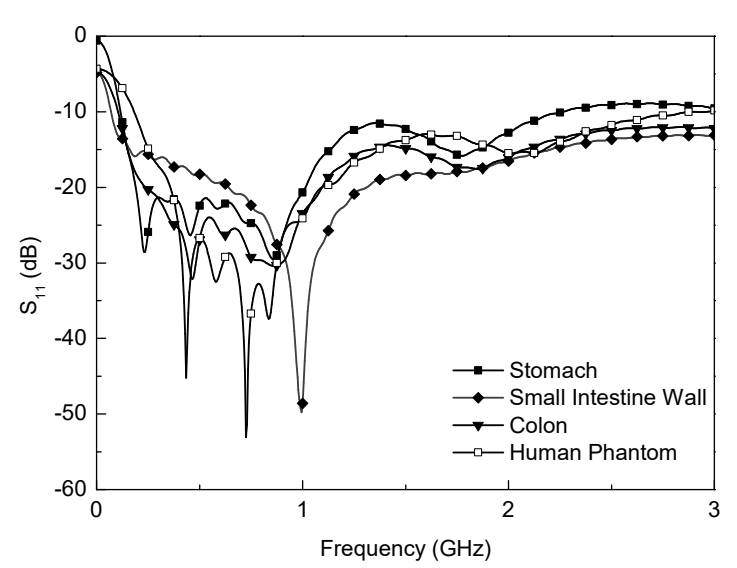

Fig. 2. Simulated return loss $\left(S_{11}\right)$ of the proposed antenna in various tissues.

with $S_{11}$ of less than $-10 \mathrm{~dB}$ is $200 \mathrm{MHz}-2 \mathrm{GHz}$, which greatly ensures the robust and stable antenna characteristics regardless of the tissue conditions. The wide bandwidth is accounted for by many parasitic capacitances introduced by the many closely spaced meandered conductor patterns. Similar effects can also be observed in previous antenna structures that have shown similar complex meandered patterns $[9,13,15]$.

\section{MEASUREMENT RESULTS}

The proposed antenna is fabricated. Its planar and cylindrical views are shown in Fig. 3(a) and (b), respectively. The antenna is measured with a differential feeding using a coaxial cable, and a balun is not used. As shown in Fig. 4, the return loss and radiation patterns of the fabricated antenna are measured after the antenna is placed at the center of a cylindrical bottle of liquid human phantom. Note that the liquid phantom is widely used in mimicking the human body [9, 13, 15-17], although minced pork can also be used $[9,12]$. The height and the diameter of the cylindrical bottle are $190 \mathrm{~mm}$ and $50 \mathrm{~mm}$, respectively. Adding salt and sugar to distilled water is known to decrease its relative permittivity while increasing its conductivity. The liquid human phantom in this work is made by a mixture of $51.8 \%$ distilled water, $46.75 \%$ sugar, and $1.45 \%$ salt, which gives $\varepsilon_{r}=$ 56.87 and $\tan \delta=0.59$ at $433 \mathrm{MHz}$ [17].

Fig. 5 shows the measured return loss in comparison with the simulation result, which exhibits an excellent agreement. The measured bandwidth is $200 \mathrm{MHz}-2.05 \mathrm{GHz}$, which corresponds to $164 \%$ of the fractional bandwidth. Note that such an ultra-wide bandwidth is highly desirable for the wireless capsule endoscope system. The wide bandwidth should result in a stable impedance matching and a robust operation for the capsule endoscope traveling through the GI tract and in a good coverage of the MICS band (402-405 MHz), the MedRadio band (401$406 \mathrm{MHz})$, and the ISM band (433.05-434.79 MHz and 902-

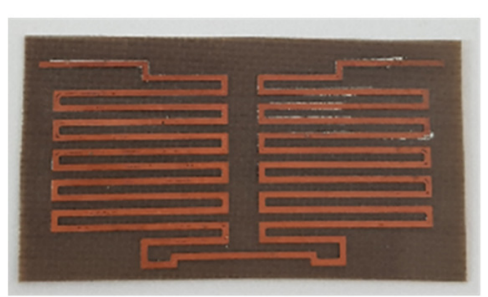

(a)

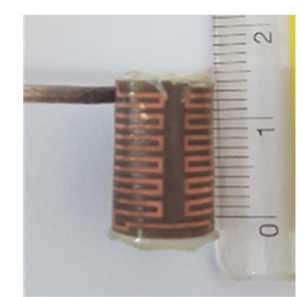

(b)
Fig. 3. Fabricated antenna in a planar (a) and a cylindrical form (b).

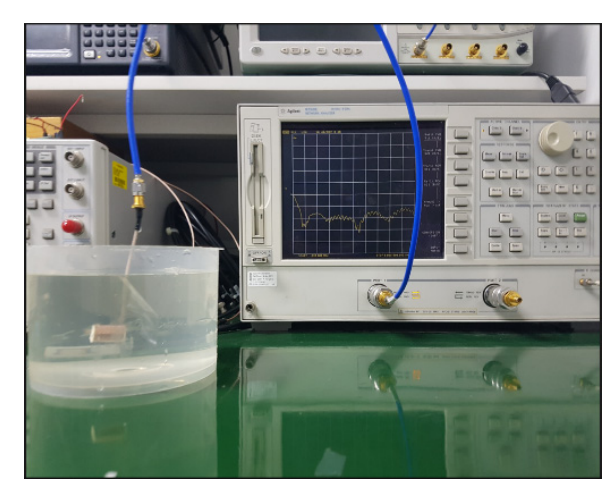

Fig. 4. Measurement setup with the fabricated antenna placed in a liquid human phantom.

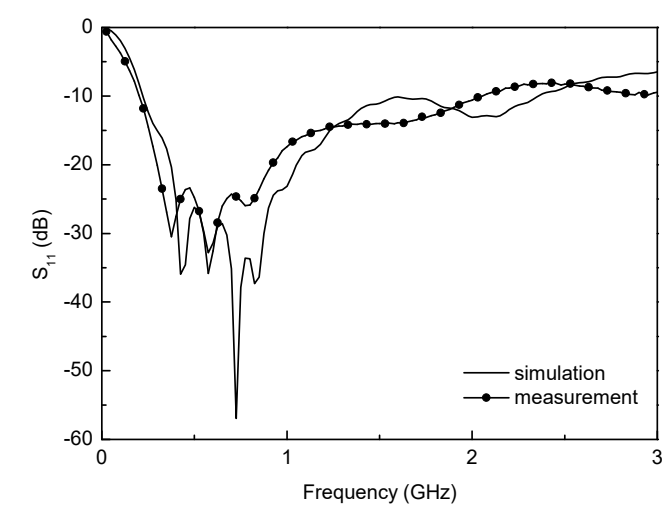

Fig. 5. Simulated and measured return loss $\left(S_{11}\right)$ of the fabricated antenna.

\section{$928 \mathrm{MHz})$.}

The radiation pattern is measured with the fabricated antenna placed in a closed bottle of liquid phantom. The radiation patterns are measured at $403 \mathrm{MHz}$. Fig. 6(a)-(c) show three different patterns at xy-cut, xz-cut, and yz-cut planes. Each plane with respect to the capsule orientation is depicted by the capsule image insets provided in each figure. As can be seen, the simulated and measured results show a reasonably good agreement. When the capsule travels through the GI tract, the orientation of the capsule is unknown and continuously changes. Therefore, to maintain a stable wireless link regardless of the capsule orientation and posture, the radiation pattern of a capsule antenna is preferred to be isotropic or at least omnidirectional $[3,5,15]$. As shown in Fig. 6 , the radiation pattern of 


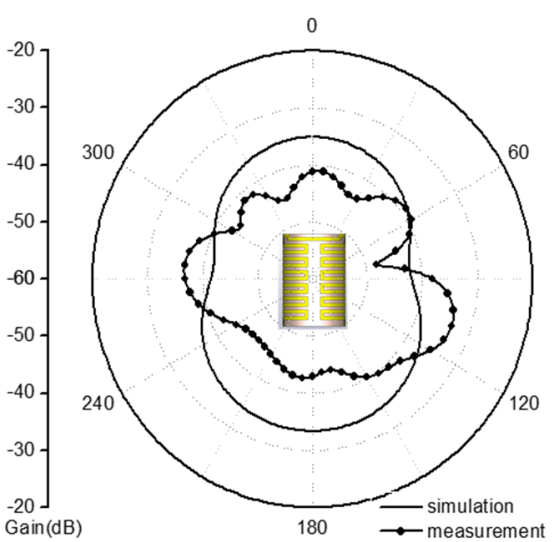

(a)

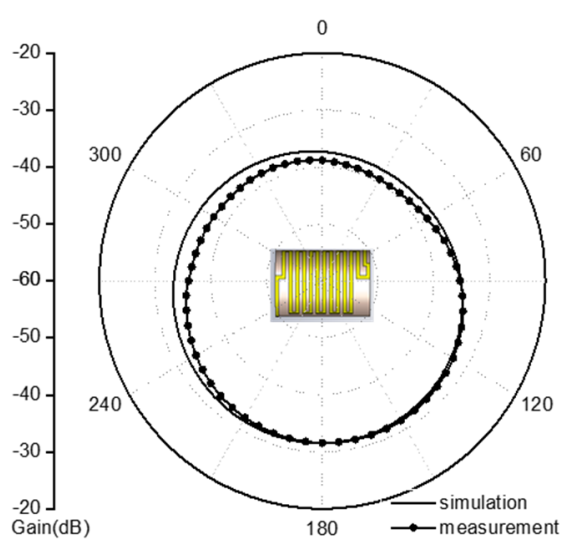

(b)

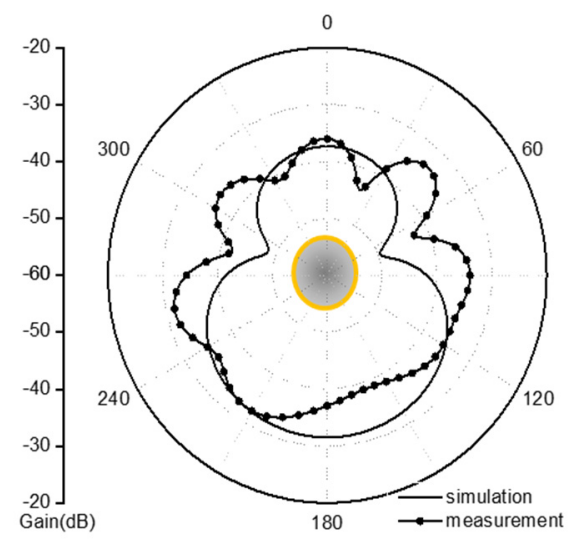

(c)

Fig. 6. Simulated and measured radiation patterns at $403 \mathrm{MHz}$ : (a) xy-cut plane, (b) xz-cut plane, and (c) yz-cut plane.

this antenna is omnidirectional. The maximum gain is found to be $-31.5 \mathrm{dBi}$ at $403 \mathrm{MHz}$.

Over-the-air wireless communication link tests are performed by employing the fabricated antenna. Fig. 7 shows the wireless communication link setup. Commercially available two RF transceiver modules are used as the transmitter and the receiver. The fabricated antenna is used at the transmitter, and a commercial dipole antenna is used at the receiver. The capsule an-

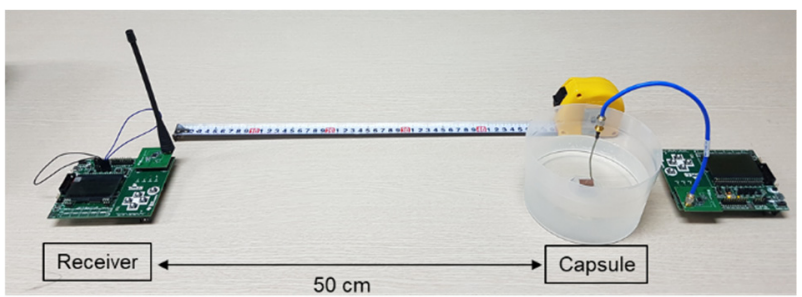

Fig. 7. Over-the-air wireless communication link test.

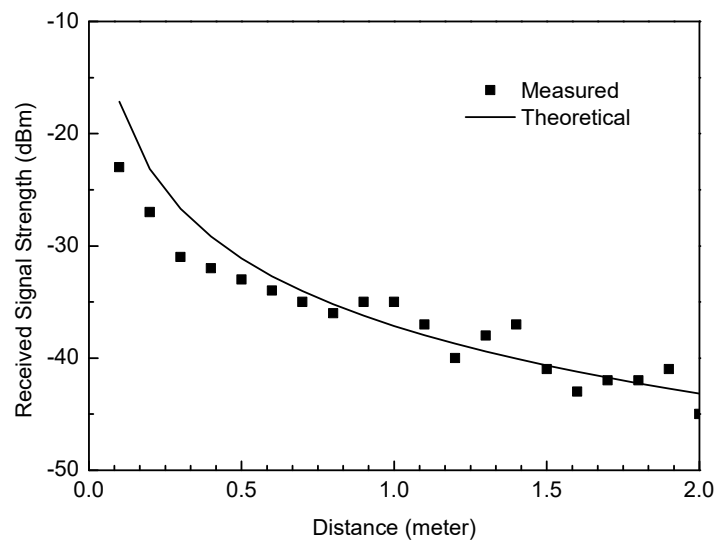

Fig. 8. Received signal strength with respect to the link distance.

tenna is placed at the center of the liquid human phantom, and the receiver is placed $50 \mathrm{~cm}$ away. The number of transmitted packet per a single link is 10,000 , and the date rate is $1.2 \mathrm{kbps}$. The transmit power is set to $0 \mathrm{dBm}$. Fig. 8 illustrates the measured received signal strength when the capsule-to-receiver distance changes from $0.1 \mathrm{~m}$ to $2 \mathrm{~m}$. A theoretically computed curve considering the free space path loss is given for comparison with the measured data. As can be seen, the theoretical and measured data show a good agreement.

Table 1 summarizes the antenna performances and compares them with those in previous works. The impedance bandwidth of the proposed antenna significantly exceeds those in previous works. This antenna also achieves the miniature form factor and a reasonable radiation gain.

\section{CONCLUSION}

We have presented a conformal ultra-wideband meandered loop antenna for wireless capsule endoscopy applications. The antenna dimensions are $14 \mathrm{~mm}$ in height and $10 \mathrm{~mm}$ in diameter. The antenna has a very wide bandwidth of $200 \mathrm{MHz}-2.05$ $\mathrm{GHz}$, which corresponds to $164 \%$ of the fractional bandwidth. It shows an omnidirectional radiation pattern, and its measured maximum gain is $-31.5 \mathrm{dBi}$. The over-the-air wireless communication link tests employing the fabricated antenna are successfully performed, proving the effectiveness of the proposed antenna for capsule endoscopy applications. 
Table 1. Performance summary and comparison

\begin{tabular}{|c|c|c|c|c|c|c|}
\hline & This work & {$[17]$} & {$[16]$} & {$[15]$} & {$[13]$} & {$[12]$} \\
\hline Antenna structure & $\begin{array}{c}\text { Meandered } \\
\text { loop }\end{array}$ & Loop & $\begin{array}{l}\text { Meandered } \\
\text { loop }\end{array}$ & $\begin{array}{l}\text { Meandered } \\
\text { loop }\end{array}$ & $\begin{array}{c}\text { Meandered } \\
\text { wire }\end{array}$ & $\begin{array}{c}\text { Meandered } \\
\text { wire }\end{array}$ \\
\hline Operating frequency $(\mathrm{MHz})$ & 433 & 433 & $\begin{array}{c}401-406 \\
433\end{array}$ & 433 & $\begin{array}{c}401-406 \\
433\end{array}$ & 433 \\
\hline Impedance bandwidth $^{\mathrm{a}}(\mathrm{MHz})$ & $200-2,050$ & $336-1,080$ & $327-530$ & $370-630$ & $284-825$ & $371-496$ \\
\hline Fractional bandwidth ${ }^{\mathrm{b}}(\%)$ & 164 & 105 & 49 & 52 & 97 & 29 \\
\hline Dimension, $\mathrm{h} \times \mathrm{d}(\mathrm{mm})$ & $14 \times 10$ & $20 \times 11$ & $17 \times 7$ & $17 \times 11$ & $15 \times 6$ & $21 \times 12$ \\
\hline Antenna gain $(\mathrm{dBi})$ & -31.5 & -28 & -28.4 & Not reported & -31.5 & -36.9 \\
\hline Substrate (dielectric constant) & $\begin{array}{l}\text { PTFE } \\
(2.17)\end{array}$ & $\begin{array}{c}\text { PPE plastic } \\
(2.55)\end{array}$ & $\begin{array}{l}\text { Polyimide } \\
\quad(3.15)\end{array}$ & $\begin{array}{c}\text { Polyimide } \\
(3.15)\end{array}$ & $\begin{array}{l}\text { PTFE } \\
(2.55)\end{array}$ & $\begin{array}{l}\text { Polyimide } \\
\quad(3.5)\end{array}$ \\
\hline
\end{tabular}

${ }^{\mathrm{a}}$ Impedance bandwidth with $-10 \mathrm{~dB}$ reflection coefficient.

${ }^{b}$ Calculated by (f_max $-\mathrm{f} \_$min) / f_center.

This work was supported by the Institute for Information and Communications Technology Promotion grant funded by the Korea government (MSIT) (No. 2016-0-00111, Development of ultra-low-power dual/wide-band MICS/BAN transceiver for capsule endoscopy; No. 2017-0-00959, University Basic IT Research Center).

\section{REFERENCES}

[1] Z. Li, Z. Liao, and M. McAlindon. Handbook of Capsule Endoscopy. China: Springer, 2014.

[2] J. Jang, J. Lee, K. Lee, J. Lee, M. Kim, Y. Lee, J. Bae, and H. J. Yoo, "4-Camera VGA-resolution capsule endoscope with $80 \mathrm{Mb} / \mathrm{s}$ body-channel communication transceiver and Sub-cm range capsule localization," in Proceedings of 2018 IEEE International Solid-State Circuits Conference (ISSCC), San Francisco, CA, 2018, pp. 282-284.

[3] S. H. Lee, J. Lee, Y. J. Yoon, S. Park, C. Cheon, K. Kim, and S. Nam, "A wideband spiral antenna for ingestible capsule endoscope systems: Experimental results in a human phantom and a pig," IEEE Transactions on Biomedical Engineering, vol. 58, no. 6, pp. 1734-1741, 2011.

[4] L. Xu, M. Q. H. Meng, H. Ren, and Y. Chan, "Radiation characteristics of ingestible wireless devices in human intestine following radio frequency exposure at 430, 800, 1,200, and 2,400 MHz," IEEE Transactions on Antennas and Propagation, vol. 57, no. 8, pp. 2418-2428, 2009.

[5] C. Liu, Y.X. Guo, and S. Xiao, "Circularly polarized helical antenna for ISM-band ingestible capsule endoscope systems," IEEE Transactions on Antennas and Propagation, vol. 62, no. 12, pp. 6027-6039, 2014.

[6] X. Cheng, J. Wu, R. Blank, D. E. Senior, and Y. K. Yoon, "An omnidirectional wrappable compact patch antenna for wireless endoscope applications," IEEE Antennas and
Wireless Propagation Letters, vol. 11, pp. 1667-1670, 2012.

[7] D. Nikolayev, M. Zhadobov, L. Le Coq, P. Karban, and R. Sauleau, "Robust ultraminiature capsule antenna for ingestible and implantable applications," IEEE Transactions on Antennas and Propagation, vol. 65, no. 11, pp. 6107-6119, 2017.

[8] Z. Bao, Y. X. Guo, and R. Mittra, "An ultrawideband conformal capsule antenna with stable impedance matching," IEEE Transactions on Antennas and Propagation, vol. 65, no. 10, pp. 5086-5094, 2017.

[9] R. Das and H. Yoo, "A wideband circularly polarized conformal endoscopic antenna system for high-speed data transfer," IEEE Transactions on Antennas and Propagation, vol. 65, no. 6, pp. 2816-2826, 2017.

[10] P. M. Izdebski, H. Rajagopalan, and Y. Rahmat-Samii, "Conformal ingestible capsule antenna: A novel chandelier meandered design," IEEE Transactions on Antennas and Propagation, vol. 57, no. 4, pp. 900-909, 2009.

[11] A. Khaleghi and I. Balasingham, "Wireless communication link for capsule endoscope at $600 \mathrm{MHz}$," in Proceedings of 2015 37th Annual International Conference of the IEEE Engineering in Medicine and Biology Society (EMBC), Milan, Italy, 2015, pp. 4081-4084.

[12] M. S. Arefin, J. M. Redoute, and M. R. Yuce, "Meandered Conformal Antenna for ISM-band Ingestible Capsule Communication Systems," in Proceedings of 2016 38th Annual International Conference of the IEEE Engineering in Medicine and Biology Society (EMBC), Orlando, FL, 2016, pp. 3031-3034.

[13] J. Wang, M. Leach, E. G. Lim, Z. Wang, R. Pei, and Y. Huang, "An implantable and conformal antenna for wireless capsule endoscopy," IEEE Antennas and Wireless Propagation Letters, vol. 17, no. 7, pp. 1153-1157, 2018.

[14] C. A. Roopnariane, M. R. Tofighi, and C. M. Collins, "Radiation performance of small implanted antennas in 
head at MICS, ISM, and GPS bands," in Proceedings of the 2010 IEEE 36th Annual Northeast Bioengineering Conference (NEBEC), New York, NY, 2010, pp. 1-2.

[15] S. Yun, K. Kim, and S. Nam, "Outer-wall loop antenna for ultrawideband capsule endoscope system," IEEE Antennas and Wireless Propagation Letters, vol. 9, pp. 1135-1138, 2010.

[16] R. Alrawashdeh, Y. Huang, and P. Cao, "Flexible meandered loop antenna for implants in MedRadio and ISM bands," Electronics Letters, vol. 49, no. 24, pp. 1515-1517,

\section{Soyeon Kim}

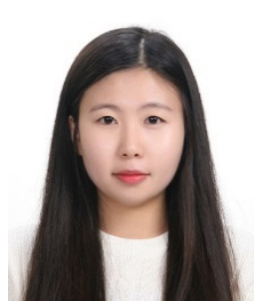

received her B.S. degree in electronics convergence engineering from Kwangwoon University in 2018. She is currently working toward her M.S. degree at the same university. Her research interests are millimeter-wave circuit and antenna for $5 \mathrm{G}$ communication.

\section{3.}

[17] M. M. Suzan, K. Haneda, C. Icheln, A. Khatun, and K. Takizawa, "An ultrawideband conformal loop antenna for ingestible capsule endoscope system," in Proceedings of 2016 10th European Conference on Antennas and Propagation (EuCAP), Davos, Switzerland, 2016, pp. 1-5.

[18] C. Gabriel and S. Gabriel, Compilation of the Dielectric Properties of Body Tissues at RF and Microwave Frequencies. London: King's College London, 1996.

Hyunchol Shin

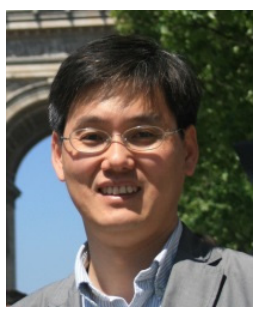

received his B.S., M.S., and Ph.D. degrees in electrical engineering from the Korea Advanced Institute of Science and Technology (KAIST), Daejeon, Korea, in 1991, 1993, and 1998, respectively. During his $\mathrm{Ph} . \mathrm{D}$., he underwent an internship as a Doktorand in 1997 at the Daimler-Benz Research Center, Ulm, Germany. Upon completion of his Ph.D., he worked in several research institutions and companies, including Samsung Electronics, Suwon, Korea, University of California at Los Angeles, CA., USA, and Qualcomm, San Diego, CA, USA, where he was involved in RF/analog/microwave circuit design for wireless communications. Since 2003, he has been with Kwangwoon University, Seoul, Korea, where he is currently a professor at the Department of Electronics Convergence Engineering. In 2010-2011, he took his sabbatical leave at Qualcomm, San Diego, CA, USA. He is the Director of the Radio Research Center for Advanced mm-Wave Beamforming Technology. He has co-authored over 80 journal and conference papers. He holds over 30 patents in the field of RF/analog circuit design. His research interests are CMOS and III-V RF/analog/millimeter-wave semiconductor circuit design for $5 \mathrm{G}, 60 \mathrm{GHz}$, and various wireless applications. Prof. Shin served on the Technical Program Committees of several IEEE conferences, such as the International Solid-State Circuits Conference (ISSCC) in 2015-2018, the VLSI Circuit Symposium (VLSI) in 2016-2018, the Asian Solid-State Circuit Conference (A-SSCC) in 2007-2012, and the Midwest Symposium on Circuits and Systems (MWCAS) in 2011. He served as the Technical Program Committee Chair and the General Chair for the International System-on-Chip Conference (ISOCC) in 2017 and 2019 , respectively. 